\title{
SABEDORIA POÉTICA NO SERTÃO: GUIMARÃES ROSA E VICO
}

\author{
Rogério Mosimann da Silva*
}

RESUMO:

A obra de Guimarães Rosa pode ser lida à luz da noção de "sabedoria poética" de Giambattista Vico. O sertão rosiano é topos dessa sabedoria. A novela "O recado do morro" ilustra esse fato, o qual aponta para a relação entre a literatura $e$ o saber filosófico.

PALAVRAS-CHAVE: Guimarães Rosa, Vico, sabedoria poética, sabedoria popular, "O Recado do morro".

\section{INTRODUÇÃO}

Há um fato na existência de João Guimarães Rosa, um ponto de intersecção entre sua biografia e sua produção literária, que chama a atenção pelo seu caráter inusitado: por que um escritor tão erudito, tão viajado, tão reconhecido, resolve voltar radicalmente os seus olhos para o universo arcaico, pré-moderno, do sertão? Para refletirmos sobre essa problemática, procuraremos desvendar, num primeiro momento, os diversos sentidos do termo sertão, tal como ele aparece na obra de Rosa. Em seguida, recorreremos ao pensador italiano Giambattista Vico. Explicitando de modo particular a sua noção de sabedoria poética, passaremos a verificar de que modo podemos afirmar o sertão rosiano como um topos de manifestação dessa sabedoria. Ilustraremos nossas considerações teóricas com a breve análise de um texto rosiano, a saber, "0 recado do morro", uma das sete novelas de Corpo de Baile. Esse itinerário nos descortinará uma série de questões que instigam o aprofundamento da relação entre o literário e outras áreas da cultura (Mitologia, História e, particularmente, Filosofia), bem como entre os saberes erudito e popular.

| Mestre em Letras: Estudos Literários (Área de concentração: Teoria da Literatura), 2003. 


\section{EM TESE}

Belo Horizonte, v. 8, p. I-243, dez. 2004

\section{JOÃO GUIMARÃES ROSA E O SERTÃO}

Cordisburgo, recordada no começo do discurso de posse na Academia Brasileira de Letras como a "pequenina terra sertaneja [...] no meio de Minas Gerais", é o berço natal de Rosa. Aị ele passou também a sua infância e vinha desfrutar as suas férias escolares. Anos mais tarde, já como escritor consagrado, Rosa se confessará, antes de tudo, um sertanejo. De fato, o mundo do sertão permeia a sua experiência existencial tanto quanto a literária.

Para Rosa, no entanto, o sertão é muito mais do que uma realidade física. Como podemos ver em sua entrevista a Fernando Camacho, a geografia se constitui num trampolim com o qual se salta para a transcendência (CAMACHO, 1978, p. 47). Precisamos cuidar, porém, que isso não nos induza ao equívoco de desprezar sem mais a concretude do ambiente. Se, por um lado, o sertão é metáfora do metafísico, apontando para uma realidade além de si, por outro ele também é metonímia e está incluído como a parte de um todo. E parte importante. Quer dizer, entre o sertão metafísico e o sertão espacial a relação não é arbitrária. Ao contrário, é na geografia física e humana do mundo do sertão que se manifesta de um modo privilegiado o sertão-mundo. Desde aí entendemos melhor porque a presença do sertão enquanto a palpável ambiência brasileira/mineira do interior (com seus particulares acidentes geográficos, seus costumes, suas crenças) aparece na obra de Rosa como uma muito empenhada opção deste.

\section{A SABEDORIA POÉTICA DE GIAMBATTISTA VICO}

Giambattista Vico (1668-1744), em flagrante polêmica com o nascente racionalismo cartesiano, refuta o paradigma matemático como fundamentação do saber. Vico parte de dois princípios epistemológicos. Pelo primeiro (a que ele denomina verum factum), só se pode realmente conhecer aquilo que se faz. Ora, sendo Deus o criador do universo, só Deus tem o verdadeiro conhecimento do mundo. Ao ser humano, cabe-1he legitimamente conhecer o "mundo civil das nações", a História, porque é ele quem a constrói. De acordo com o segundo princípio, conhecemos algo quando conhecemos 
como esse algo se originou, como começou. É preciso, pois, investigar os albores da presença humana na Terra para desentranhar desde aí a lógica própria do desenrolar histórico. Como estamos vendo, o projeto intelectual de Vico, sobre o qual ele se debruçou por décadas e que the custou o dispêndio de grandes energias e não poucas incompreensões, coincide com uma ampla Filosofia da História, uma interpretação global das leis que regeriam o caminhar humano sobre o planeta ao longo dos séculos.

Vico era bem consciente das dificuldades de tal empreendimento, e somente a sua tenaz perseverança é que The permitiu publicar a sua Ciência Nova, na versão definitiva de 1744, ano de sua morte. 0 pensador napolitano, aproveitando sua eminente erudição, reúne a gama de informações disponíveis na época, e que depois desembocariam em diferentes ciências autônomas (Arqueologia, Lingüística, Filologia, Sociologia, Antropologia Cultural, História, etc), para formar um monumental afresco da História, no dizer do seu tradutor Marco Lucchesi.

Carente dos dados que essas ciências só pesquisariam e forneceriam posteriormente, e sabedor de que os primeiros povos não nos legaram documentos, Vico, fiel mais uma vez aos princípios de sua Ciência e fazendo uso de sua capacidade imaginativa e especulativa, parte para uma jornada solitária em busca de como teriam vivido os pais da humanidade.

Suas conclusões são surpreendentes. Com fina ironia, critica a pretensão dos doutos que, parece, esperariam ver os membros desses povos ditos primitivos como freqüentadores da escola de Aristóteles. Vico contesta isso com veemência, considerando grave erro atribuir aos povos antigos um raciocínio próprio dos tempos filosóficos. Para Vico, ao invés das serenas considerações, esses povos se caracterizavam por extremadas paixões (emoções) e por uma robusta fantasia. Não dominando a generalização abstrata do conceito, empregavam os caracteres poéticos, condensação, em um personagem humano, de uma dada realidade ou grupo social. 0 exemplo maior é Homero, a quem Vico reserva um capítulo inteiro, caráter poético de todos os cantadores populares.

Vico identifica três idades no decorrer da História. Primeiro, a dos deuses, que possui esse nome porque as realidades naturais eram associadas a divindades (por exemplo, os raios e trovões figuravam Júpiter). Recém terminado o dilúvio, robustos humanóides, com estatura de gigantes, vagavam pela grande selva da terra. Nesse ponto germinal da humanidade, fronteira entre a bestialidade e uma existência reconhecível como humana, a linguagem se reduzia a grunhidos e gestos. 


\section{EMTESE}

Belo Horizonte, v. 8, p. I-243, dez. 2004

Segue-se a idade dos heróis, à qual Vico dedica a maior parte de seu livro. Privados do pensamento demonstrativo, os habitantes da cidade antiga se expressam em um linguajar fantasioso, através das fábulas (mitos). Assim abordam a realidade e assim explicam (adequadamente) tudo o que faz parte de seu horizonte. Sendo o pensar por imagens (metáforas) o seu modo próprio de conhecer, Vico conclui: os primeiros povos eram naturalmente poetas. Tal afirmação se constitui numa de suas intuições centrais e mais brilhantes.

A terceira idade é a dos homens. Nesta, a razão aparece plenamente desenvolvida, em sua modalidade lógico-demonstrativa, apodítica. É a idade das reflexões filosóficas e das teorias científicas. Caracteriza-se pela autoconsciência do processo cognitivo e pelo ideal de obediência às regras estabelecidas para um discurso coerente.

Vico não despreza, de forma alguma, o advento da Razão. Contudo, ele é bastante crítico em relação aos seus desdobramentos históricos. Posiciona-se duramente contra a vaidade das nações, pela qual, por exemplo, a sociedade moderna, racionalizada, se posta como o supra-sumo de toda manifestação cultural, e julga anacronicamente as demais idades, sem reconhecer-1he a sua especificidade e seus valores próprios. E com a mesma agudeza reage à vaidade dos doutos, que se deixam inchar orgulhosamente, apegados a suas lucubrações eruditas, menosprezando outras formas de aproximação ao real.

A concepção de História em Vico é circular-espiralada. A sucessão das idades forma um curso (corso) e o término de um ciclo coincide com o início de um outro, originando-se um re-curso, recorrência (ricorso). Tudo guiado pela Providência divina. Vico, porém, continua afirmando a liberdade e autonomia humanas e não cai no determinismo. Entende sim os corsi e ricorsi como a lógica geral da História, comum a todos os povos, mas nem afirma que essa esteja previamente definida em seus detalhes, nem que cada etapa deva ser necessariamente cumprida.

Vico, longe de ver na seqüência das três idades uma mera linearidade ascensional, defende, ao contrário, que cada uma delas possui o seu modo próprio de abordar a realidade, a sua linguagem própria, a sua lógica própria, a sua peculiar visão-de-mundo. E que, como tal, cada etapa da História deve ser respeitada e compreendida. 
Por isso mesmo é que Vico não admite que a idade dos homens seja considerada, por si só, superior às demais. Sem dúvida, ela traz benefícios, progresso tecnológico e material, conforto, avanços políticos, etc. Mas, ao mesmo tempo, ela implica no declínio do poético, além de não nos livrar das guerras fratricidas, da fome, de tantos males evitáveis. Comparado à época da barbárie primitiva, somos chamados a reconhecer que o mundo que se crê regido pelo racional, em muitos aspectos, suplanta-a em destrutividade. Essa barbárie da razão, tempo de decadência, instaura-se quando a razão se torna instrumental, mero meio, pura técnica, desvinculada de fins éticos.

Para entender a dinâmica histórica, Vico esmiúça detidamente os vestígios que a humanidade primitiva disseminou na linguagem. Através dessa análise lingüística, é possível desvendar a mentalidade própria dos primeiros povos, que é uma lógica poética, isto é, um dado modo de conceber e usar a linguagem, de acercar-se da realidade não através da razão demonstrativa, da verificação científica, do conceito filosófico, e sim por intermédio das imagens, metáforas. E aqui chegamos a uma noção central de Vico, que é a sabedoria poética. Sabedoria porque se trata de uma forma de conhecimento não principalmente teórico, mas prático, existencial, ético. Poética, justamente porque privilegia a fantasia, a metáfora - um pensar por imagens.

Mas se as idades viquianas, como vimos, não se sucedem linearmente, isso significa também que há uma coexistência entre o que é específico em cada uma das épocas. Ou seja, a passagem para uma nova etapa histórica não apaga totalmente os traços da etapa anterior. Isso permite afirmar a sobrevivência do poético como uma dimensão do humano, uma marca antropológica ou atitude ("mente poética em tempos analiticos", como bem o formula Alfredo Bosi, referindo-se a Vico). 0 falar das crianças e o dos considerados loucos, bem como as manifestações artísticas, constituemse em ilustração viva dessa permanência do arcaico no moderno, do poético no horizonte de uma sociedade racionalizada. Não se trata, é claro, de sustentar uma apologia do irracionalismo. Apenas se está a acentuar a persistência de uma palavra que alarga, para além dos estreitos limites do apodítico, os horizontes da lógica. 


\section{EM TESE}

Belo Horizonte, v. 8, p. I-243, dez. 2004

\section{O SERTÃO ROSIANO COMO REDUTO DE SABEDORIA POÉTICA}

Guimarães Rosa, ao localizar grande parte de sua obra no ambiente geográfico do sertão e a totalidade da mesma num horizonte de compreensão sertanejo, situa-se no universo do poético, está imerso nele. Movimenta-se, assim, na esteira de Vico. Sem que esse caminho trilhado signifique influência ou herança direta, não há como se negar a proximidade entre esses dois autores. Ajuda-nos a entender esse fato a noção de sinfronismo, com a qual se designa a semelhança de concepções entre pessoas bastante distanciadas no tempo e no espaço. Entre essas, constata-se alguma afinidade, uma coincidência na maneira de encarar o real, um horizonte comum, uma atitude análoga diante da vida, da arte, etc (MACHADO, 1976, p. 104-105).

Nesse sentido é que podemos dizer, com Edoardo Bizzarri, que a poética de Vico e a de Rosa se abraçam, comungando da mesma ênfase à fantasia, à imaginação, desbancando o moderno ideal cartesiano de uma ciência objetiva, fundada no paradigma matemático.

Médico formado e com considerável tempo de atuação clínica, erudito, profundo conhecedor de inúmeras línguas, diplomata de carreira com larga experiência internacional, autodidata, leitor voraz dos mais variados campos do saber, e, além do mais, escritor de profunda consciência em relação ao seu processo de criação, não resta dúvida que Rosa nem desconhecia nem menosprezava as operações mentais necessárias para elaborar a sua obra tão meticulosamente entretecida. E, no entanto, ele se autoproclamava um sertanejo, reivindicando como companheiros nada menos do que Goethe, Unamuno, Dostoievsky. A inclusão de autores tão distanciados da geografia brasileira do interior só se faz possível, então, se realmente admitimos que "o sertão está em toda parte", que "o sertão é o mundo" (como nos ensina o jagunço Riobaldo, em Grande Sertão: Veredas).

Por outro lado esse sertão-mundo transparece de maneira mais visível no mundo do sertão, ali onde as explicações conceituais, o progresso técnico moderno, mal chegam a tangenciar. Imune ainda às manifestações de uma racionalidade demonstrativa, à megera cartesiana (expressão empregada por Rosa em carta a Bizzarri), o sertão é o lugar do mítico e do místico, do extraordinário, do mágico, do poético... E nessas populações esquecidas, nesse cotidiano aparentemente amorfo e 
inexpressivo, rotineiro, sem-graça, escondem-se outras possibilidades de vida e de Graça, virgens, latentes, à espera de germinação. De quem, às vezes, menos se espera, vêm os vislumbres de novos caminhos de (re)construção histórica. Do sertão, por exemplo: mundo à margem, marginalizado, e terreno dos marginais da razão.

\section{RECADOS DO (EU) MORRO}

Edoardo Bizzarri, tradutor de Rosa, considera que toda a obra do escritor mineiro pode ser proficuamente estudada a partir de um viés viquiano, mas particularmente o Corpo de Baile e, sobremaneira, "0 recado do morro" (BIZZARRI, 1972).

Nessa novela narra-se uma expedição pela região sertaneja de Cordisburgo, sob a guia do enxadeiro Pedro Orósio. Pedro - pedra, montanha (orós, em grego) - é respeitado e temido por todos, por ser alguém forte e de elevada estatura. É também um inveterado namorador, o que desperta o ciúme de muitos rapazes. Ivo, por exemplo, seu atual parceiro de viagem, está a arquitetar um plano de traição. Pedro segue seu caminho desavisadamente.

Sob a aparente simplicidade, "0 recado do morro" é uma narrativa bastante complexa, com uma rica sobreposição de camadas semânticas, algo impossível de destrinçar nestas poucas páginas. Aludamos, ao menos, à simbologia planetária que perpassa o texto: Pedro representa a Terra, e o Ivo, que tem por alcunha Crônico, é Cronos/Saturno, o tempo. Por trás, pois, de um prosaico duelo entre dois jovens que disputam a mesma moça, dissimula-se o embate entre o ser humano e a permanente sombra da morte, a finitude da existência.

No decorrer da estória surgem bizarros personagens: cinco loucos (ou dementes, ou fracos do juízo, ou alucinados), um menino pequeno, e um cantador popular. São os recadeiros, elos receptores-transmissores de uma cadeia de mensagem que se inicia quando o primeiro deles afirma ter escutado o Morro da Garça pronunciarThe um aviso. Esse primeiro recadista é o Gorgulho, palavra que, entre outros, guarda o significado de cascalho, restos de pedra sem nenhum valor, mas cascalho em meio ao qual se pode encontrar ouro. É clara metáfora da própria condição desses personagens, todos eles apresentados como pessoas marginalizadas e também como 


\section{EMTESE}

Belo Horizonte, v. 8, p. I-243, dez. 2004

marginais em relação ao mundo moderno regido pela razão. Todavia, são esses seres marginais que se revelam os portadores de sabedoria, e sabedoria em sua forma poética. Captam e exprimem uma mensagem não por vias racionais, mas pelos canais da intuição. 0 aviso chegara todas as vezes aos ouvidos de Pedro Orósio, mas só no final, quando transformado em canção pelo artista Laudelim, último recadeiro, é que The faz palpitar o coração, entusiasma-1he. Arte da palavra e arte musical conjugamse para ajudar que Pedro decifre sua vida no espelho do texto de tal canção, plena de sabedoria popular recolhida, em feixe. Pedro se lê e, desse modo, escapa às maquinações traiçoeiras do Ivo. ${ }^{1}$

Pedro Orósio revela-se, assim, como sendo cada um de nós, cada ser humano, criatura finita que somos, mas com abertura ao infinito e com ansiado afã de eternidade. Não por acaso, Pedro experimenta constante e vigorosa saudade de sua terra natal e busca-a como sua pátria definitiva, um Lá ao qual o texto nos remete de ponta a ponta.

Essa revelação vem cifrada já no título da novela: recado do (eu) morro. E é pelos lábios dos populares recadeiros marginais, e não pela voz autorizada de algum douto e estudado, que ressoa esse recado "de vida e de morte, extraordinariamente comum" (linhas iniciais da novela) que ajuda não apenas o personagem como também o leitor no desafio de ir desenredando, dia-a-dia, os insondáveis mistérios da existência.

\section{LITERATURA, UM HETEROLOGOS}

A obra em análise tematiza, pois, questões suficientemente relevantes da existência humana finita e emoldurada pelo tempo, em permanente defrontar-se com o enigma da morte. Sobre elas, Rosa reflete não redigindo um tratado filosófico. Ele simplesmente conta uma estória. Ou seja, exercita literariamente aquilo que seus personagens vivenciam: um conhecimento prático, uma sabedoria, em forma poética.

E nos encontramos, então, com uma dimensão da arte literária, bastante candente hoje em dia: sua relação com outras formas de saber. Por exemplo, a relação entre Literatura e Filosofia. Postula-se, assim, um modo de relacionamento mais simétrico entre essas diferentes manifestações culturais. Pondo em cena ações e 
personagens ficcionais, e através deles refletindo poeticamente acerca de questões antropológicas fundamentais, a literatura em nada fica devendo ao conceito, às explicações lógico-racionais. É uma outra forma de conhecimento, que reivindica a sua autonomia e conclama a que se compartilhem os passos na mesma larga estrada do peregrinar humano, e que chama ao diálogo entre a sabedoria filosófica e a sabedoria poética, ao mesmo tempo em que convida à auscultação da milenar e menosprezada experiência da sabedoria popular.

NOTA:

1. "Decifragem da vida no espelho do texto" é expressão que tomamos de empréstimo do filósofo Paul Ricoeur.

ABSTRACT :

The work of Guimarães Rosa may be read under the light of Giambattista Vico's notion of "poetic wisdom". Rosa's "sertão" (Brazilian backlands) is the topos of this wisdom. The novella "O Recado do Morro" illustrates this fact, which points to the relation between literature and philosophical knowledge.

KEY WORDS: Guimarães Rosa, Vico, poetic wisdom, popular wisdom, "O Recado do Morro".

\section{REFERÊNCIAS BIBLIOGRÁFICAS}

ARAÚj0, Heloísa Vilhena de. A raiz da alma: Corpo de Baile. São Paulo: Edusp, 1992.

BIZZARRI, Edoardo. Guimarães Rosa e Vico: notas sobre uma poética rosiana. 0 Estado de São Paulo, suplemento literário, 19/11/1972.

BURKE, Peter. Vico. São Paulo: UNESP, 1997.

CAMACHO, Fernando. Entrevista com João Guimarães Rosa. Humboldt, Berna, n. 37, 1978, p. 42-53.

MACHADO, Ana Maria. Recado do nome (leitura de Guimarães Rosa à luz do nome de seus personagens). Rio de Janeiro: Imago, 1976.

ROSA, João Guimarães. Correspondência com seu tradutor italiano Edoardo Bizzarri. 2. ed. São Paulo: T. A. Queiroz Ed. / Instituto Cultural Ítalo-Brasileiro, 1980. 


\section{EMTESE}

Belo Horizonte, v. 8, p. I-243, dez. 2004

ROSA, João Guimarães.0 recado do morro. In: No Urubuquaquá, no Pinhém: Corpo de Baile. 6. ed. Rio de Janeiro: José 01ympio, 1978.

VARELA, Maria Helena. O heterologos em língua portuguesa (elementos para uma antropologia filosófica situada). Rio de Janeiro: Espaço e tempo, 1996.

VICO, Giambattista. A Ciência Nova. Trad. Marco Lucchesi. Rio de Janeiro / São Paulo: Record, 1999. 